\title{
Evapotranspiration From Douglas Fir Stands Exposed to Soil Water Deficits
}

\author{
T. A. BLACK \\ Department of Soil Science, University of British Columbia, Vancouver, British Columbia V6T IW5
}

\begin{abstract}
The rate of evapotranspiration from thinned and unthinned stands of Douglas fir was measured using energy and water balance methods. At high values of soil water storage in the root zone the evapotranspiration rate was approximately $80 \%$ of the equilibrium evaporation rate. Below a critical value of soil water storage the ratio of the evapotranspiration rate to the equilibrium evaporation rate $\left(E / E_{\text {ea }}\right)$ tended to decrease linearly with decreasing soil water storage. The critical values of soil water storage in the root zone were 11.8 and $8.3 \mathrm{~cm}$ for the thinned and unthinned stand, respectively. Below these critical storage values, there was approximately $3.5 \mathrm{~cm}$ of water remaining in both root zones that was extractable by the trees. The relationship between $E / E_{\text {eq }}$ and the fraction of extractable water in the root zone for both stands was very similar for sunny days. In this relationship, $E / E_{\mathrm{eq}}$ began to decrease when there was approximately $40 \%$ of the extractable water remaining in the root zones of both stands.
\end{abstract}

\section{INTRODUCTION}

A practical approach to describing how supply and demand factors affect water use by crops and forest is to relate the ratio of the actual to the maximum evapotranspiration rate to soil water content or potential of the root zone. Several workers studying agricultural crops have reported evapotranspiration data in this form [e.g., Denmead and Shaw, 1962; Gardner and Ehlig, 1963; Van Bavel, 1967; Ritchie et al., 1972; Davies and Allen, 1973].

This general approach is used in this paper to describe rates of water use by two West Coast Douglas fir stands that are usually exposed to midsummer drought. The objectives of this paper are to report the maximum rates of evapotranspiration when root zone soil water content is high and to describe the variation in the evapotranspiration rate as the root zone soil dries out.

\section{General Considerations}

The maximum rate of evapotranspiration required in the above approach has been obtained in several ways. Denmead and Shaw [1962] used the measured rate at the field capacity value of soil water content. Some variations of the Penman [1948] equation have been used by other workers [Tanner and Pelton, 1960; Van Bavel, 1967; Ritchie, 1973]. Priestley and Taylor [1972] showed that for well-watered crops at several experimental sites the maximum 24-hour rate of evapotranspiration $\left(E_{\max }\right)$ was approximately equal to the equilibrium evaporation rate multiplied by 1.26 . The term equilibrium evaporation rate $\left(E_{\mathrm{eq}}\right)$ is used by many micrometeorologists and is defined as follows [Slatyer and Mcllroy, 1961; McNaughton, 1976]:

$$
E_{\text {eq }}=[s /(s+\gamma)]\left(R_{n}-G-M\right) / L
$$

where $s$ is the slope of the saturation vapor pressure curve, $\gamma$ is the psychrometric constant, $R_{n}$ is the net radiation flux, $G$ is the soil heat flux, $M$ is the rate of canopy heat storage, and $L$ is the latent heat of vaporization of water.

There has been a good deal of experimental support of the conclusion of Priestley and Taylor from workers studying lowgrowing plant communities with no shortage of water [e.g., Davies and Allen, 1973; R. B. Stewart and W. R. Rouse, 1977]. However, other workers have found that while $E_{\max }$ was a linear function of $E_{\text {eq }}$, the proportionality coefficient could be

$$
\text { Copyright } \odot 1979 \text { by the American Geophysical Union. }
$$

either greater or less than 1.26 [e.g., Jury and Tanner, 1975; McNaughton and Black, 1973]. McNaughton and Black found that in an 8-m tall Douglas fir forest with no soil water shortage, $E_{\max }$ was approximately equal to $E_{\text {eq }}$. In this paper, $E / E_{\mathrm{eq}}$ ratios will be reported for a range of soil water conditions and will therefore provide an indication of $E_{\max } / E_{\mathrm{eq}}$ under conditions of high soil water content. (The latter ratio is often given the symbol $\alpha$ in the micrometeorological literature.)

Many workers have observed that at a critical soil water content or matric potential the rate of evapotranspiration begins to decline. Denmead and Shaw [1962] found that this critical water content increased with increasing atmospheric demand for water. Priestley and Taylor [1972] found during the drying phase (i.e., for water contents less than the critical value) that $E / E_{\max }$ appeared to be linearly related to root zone soil water storage. In analyzing the results of 24 crop evapotranspiration experiments, Tanner and Ritchie [1974] converted all soil water content data to fractional extractable water in the root zone $\left(\theta_{e}\right)$ defined as follows:

$$
\theta_{e}=\left(W-W_{m}\right) /\left(W_{F}-W_{m}\right)
$$

where $W$ is the root zone water storage, $W_{m}$ is the minimum water storage at which the rate of water extraction by the plants approaches zero, and $W_{F}$ is the water storage at field capacity (when drainage is small in relation to evapotranspiration). They found that during the drying phase, $E / E_{\max }$ was linearly related to $\theta_{e}$. Furthermore, they found that with nearly all of the data examined, the critical value of $\theta_{e}$ was between 0.25 and 0.35 . An objective of this paper will be a report on how closely two Douglas fir forest stands conform to these findings.

\section{Experimental Procedure}

\section{Experimental Sites}

The research was carried out in two large stands of Douglas fir (Pseudotsuga menziesii (Mirb.), Franco) trees of densities 1840 trees/ha (site 1, unthinned) and 840 trees/ha (site 2, thinned) planted in 1953. In the thinned stand, over half the thinning (from 1470 trees/ha) was done in 1974, and it was completed in May 1975. Both sites (about $1 \frac{1}{2} \mathrm{~km}$ apart) were located at an elevation of $150 \mathrm{~m}$ on generally flat terrain on the east coast of Vancouver Island about $27 \mathrm{~km}$ northwest of Courtenay, British Columbia, on Crown Zellerbach Company land. Further description of the sites is given by Tan and Black [1976] and Nnyamah and Black [1977]. 
TABLE 1. Retention Properties of Dashwood Gravelly Sandy Loam at Sites 1 and 2

\begin{tabular}{|c|c|c|c|}
\hline & $\begin{array}{c}\text { Field } \\
\text { Capacity } \\
\left(-\frac{1}{3} \text { har }\right)\end{array}$ & $\begin{array}{c}\text { Permanent } \\
\text { Wilting Point } \\
\text { ( }-15 \text { bars })\end{array}$ & $\begin{array}{c}\text { Available } \\
\text { Water }\end{array}$ \\
\hline \multicolumn{4}{|c|}{ Site I } \\
\hline$\stackrel{\theta}{W, \mathrm{~cm}}$ & $\begin{array}{l}0.215 \\
14.0\end{array}$ & $\begin{array}{l}0.080 \\
5.2\end{array}$ & $\begin{array}{l}0.135 \\
8.8\end{array}$ \\
\hline \multicolumn{4}{|c|}{ Site 2} \\
\hline $\begin{array}{l}\theta \\
W, \mathrm{~cm}\end{array}$ & $\begin{array}{l}0.213 \\
17.0\end{array}$ & $\begin{array}{l}0.110 \\
8.8\end{array}$ & $\begin{array}{l}0.103 \\
8.2\end{array}$ \\
\hline
\end{tabular}

The average volumetric water content of the root zone $(\theta)$ is equal to the root zone water storage $(W)$ divided by the depth of the root zone. Root zone depths were assumed to be 65 and $80 \mathrm{~cm}$ at site 1 and site 2 , respectively.

Trees at site 1 were $8-10 \mathrm{~m}$ tall, while those at site 2 were 7-9 $\mathrm{m}$ tall. There was almost no undergrowth at site 1 , but at site 2 there was considerable salal (Gaultheria shallon, Pursh) undergrowth. The leaf area index at site 1 was between 7.5 and 8.0 (projected leaf area basis), while at site 2 it was approximately 6.6 (3.6 for Douglas fir and 3.0 for salal) .[Tan et al., 1978].

The soil texture at both sites is gravelly sandy loam of the Dashwood series. The soil is underlain by sandstone at a maximum depth of $70 \mathrm{~cm}$ at site 1 and $85 \mathrm{~cm}$ at site 2 . The physical properties of the soil are described in detail by Nnyamah and Black [1977]. Soil water retention properties for the root zones at both sites are given in Table 1 .

\section{Measurements}

Site 1 was instrumented in the summer of 1974 , and site 2 in the summer of 1975 . Soil water matric potential $\left(\psi_{m}\right)$ was measured at least 3 times daily using a tensiometer-pressure transducer system and Wescor PT51-10 hygrometers at four depths at site 1 and five depths at site 2. Using gradients of the total soil water potential at the base of the root zone and the unsaturated hydraulic conductivity characteristic, Nnyamah and Black [1977] estimated the rate of vertical flow of water into or out of the root zones at both sites. Weekly soil water content measurements were made gravimetrically in the 0 - to $10-\mathrm{cm}$ layer and by neutron moisture meter (calibrated at each site) down to the $50-\mathrm{cm}$ and $75-\mathrm{cm}$ depths at site 1 and site 2, respectively. From these measurements the water storage in

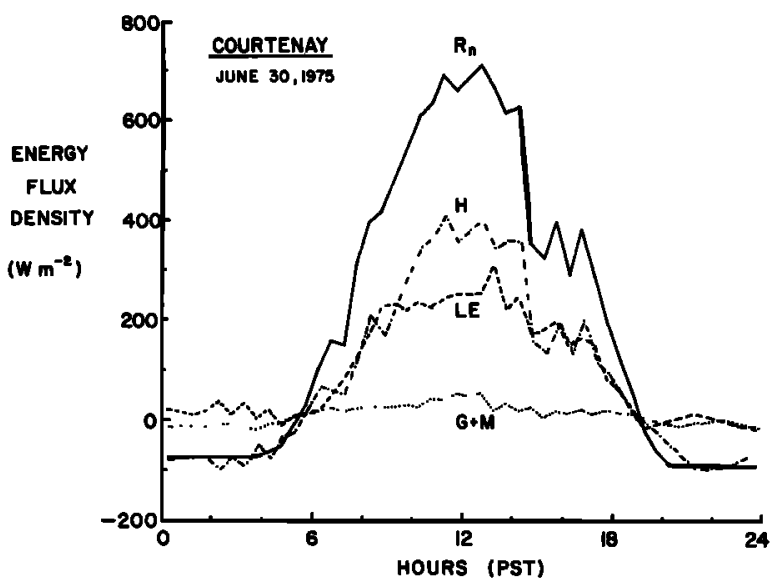

Fig. 1. Energy balance diagram for June 30, the second day of the main summer drying period in 1975, at site 2 (thinned stand) at Courtenay, British Columbia. The variables are defined in the text. the entire root zone could be calculated [Nnyamah and Black, 1977]. Average values of the evapotranspiration rate $E$ were calculated for successive 5- to 10-day intervals during drying periods of about 1-month duration (each drying period followed heavy rain) at each site. Calculations were made using the following water balance equation:

$$
E=-\Delta W / \Delta t-D+P
$$

where $\Delta W$ is the change in root zone soil water storage over the time interval $\Delta t, D$ is the average rate of drainage from the root zone over the time interval ( $D$ was positive during only part of the first week following the end of the heavy rain that wetted the entire root zone), and $P$ is the average rainfall rate over the time interval. Surface runoff was not observed at either site throughout the duration of the study.

Half-hourly measurements of evapotranspiration were made using the energy balance/Bowen ratio method. The Bowen ratio $\beta$ was measured using a psychrometric apparatus described by Black and McNaughton [1971]. The separation between the two psychrometric sensing heads was $1 \mathrm{~m}$ at site 1 and $3 \mathrm{~m}$ at site 2 . The importance of the increased head separation will be discussed later in the paper. The evapotranspiration rate was calculated using the equation

$$
E=\left(R_{n}-G-M\right) /[L(1+\beta)]
$$

Detailed description of the measurement of $R_{n}, G$, and $M$ at the Courtenay sites is given by Tan and Black [1976]. At site 1, energy balance measurements of $E$ were made on 18 sunny days between June 17 and August 14, 1974. After further examination of these data, values on 4 days were not considered in this paper because of their lower reliability. Since $R_{n}$ and $\Psi_{m}$ were measured throughout this period, $E$ on the remaining days was estimated from the relationship between $L E / R_{n}$ and $\Psi_{m}$ obtained from the 18 days of $E$ measurements reported by Tan and Black [1976]. At site 2, $E$ was measured from June 30 to August 11, 1975, except for July 8, 9, and 10 , when it was estimated as described above.

\section{RESULTS AND Discussion}

\section{Energy balance measurements}

Figures 1, 2, and 3 show energy balance diagrams for three sunny days at different stages of the main dry period of weather in 1975 at site 2 . June 30 was the second day since rain fell (June 28), and soil water matric potentials in the root zone varied from -0.1 to -0.4 bar. The sensible heat flux exceeded the latent heat flux (i.e., $\beta>1$ ) well into the early part of the afternoon and would have continued this way were it not for the occurrence of midafternoon cloud. Very similar daytime Bowen ratios were observed on June 29. This is in contrast to the energy balance diagrams of McNaughton and Black [1973] for an 8-m tall Douglas fir forest at the University of British Columbia Research Forest at Haney, British Columbia. In the latter case, by late morning the latent heat flux exceeded the sensible heat flux, and by midafternoon the former considerably exceeded the latter. The energy balance diagrams for July 22 and July 28 show a progressive increase in the sensible heat flux and a decrease in the latent heat flux as the soil water content of the forest root zone decreased. On July 29 the stomata were more closed than on July 28 , thus causing $\beta$ to be even greater on July 29 . On July 30 and 31 , some stomatal opening caused a decrease in $\beta$. Tan et al. [1978] have suggested that the stomatal opening was due to a slight decrease in 
the vapor pressure deficit of canopy air or an improvement in tree water status as a result of marked stomatal closure on July 29. The importance of this variation in daily evapotranspiration will be further discussed later in the paper. Tan and Black [1976] have reported daily net radiation and latent heat flux trends for site 1 studied in 1974.

Figure 4 shows a graphical summary of daily (24-hour) values of energy balance measurements of evapotranspiration rate made at site 2 in 1975. Also shown in this figure are daily (24-hour) values of the available energy $\left(R_{n}-G-M\right)$ and the values of daily (24-hour) mean temperature. Toward the beginning of the main dry period, roughly $50 \%$ of the available energy was used in evapotranspiration, while near the end (rain occurred on August 1), roughly $20 \%$ was used in evapotranspiration. Toward the beginning of the dry period the evapotranspiration rate was between 3 and $4 \mathrm{~mm} \mathrm{~d}^{-1}$, while near the end, it was between 0.75 and $1.75 \mathrm{~mm} \mathrm{~d}^{-1}$.

\section{Comparison of Energy and Water Balance \\ Estimates of Evapotranspiration}

Figure 5 shows the trends of water balance estimates of evapotranspiration during a summer drying period at site 1 and site 2 . Also included in this figure is the average value of the net radiation for each of the intervals. Notice that the water balance values of evapotranspiration at site 2 agree well with averaged values of the energy balance estimates shown in Figure 4. The value of evapotranspiration at the beginning of the drying period in 1974 was lower because the first 10 days following rain had considerable cloud and consequently low net radiation as shown in Figure 5 . The ratios of latent heat flux to net radiation for the first 10 days following rain at the two sites were similar (site 1, 53\%; site 2, 49\%).

Energy and water balance estimates of evapotranspiration from both stands are compared in Figure 6. The water balance values are the same as those in Figure 5. The energy balance values are average evapotranspiration values for all days making up each water balance time interval. For site 2 these energy balance values are those shown in Figure 4. As can be seen in Figure 6, there is good agreement between water and energy balance estimates of evapotranspiration at site 2 . The regression equation in Figure 6 indicates that energy balance values averaged $1 \%$ higher than the water balance values. The regression equation for site 1 shows that energy balance values averaged $12 \%$ higher than water balance values. Water balance estimates for site 1 should be more accurate than those for site 2 because the unsaturated hydraulic conductivity characteristic used in calculating vertical soil water flux at both sites was determined on a soil sample from site 1 [Nnyamah and Black. 1977]. The accuracy of energy balance measurements at site 1 was less than that at site 2 for two reasons. First, a forestry access road passed within $50 \mathrm{~m}$ of the meteorological tower, and wind direction was from the road to the tower for a significant fraction of the time. Second, the 1-m separation distance between the sensing heads of the Bowen ratio measurement apparatus, when operating at site 1, was a minimum acceptable distance in view of the small size of the measured vertical gradients of temperature and humidity. Increasing this distance to $3 \mathrm{~m}$ at site 2 proved most satisfactory, as can be seen in the stability of the latent and sensible heat flux data in Figures 1-3. Sensor separation at site 2 was increased, since gradients had been observed to be small at site 1 and were expected to be smaller above the thinned stand at site 2 . During the daytime on a sunny day when soil water content was relatively high, typical dry and wet bulb gradients were

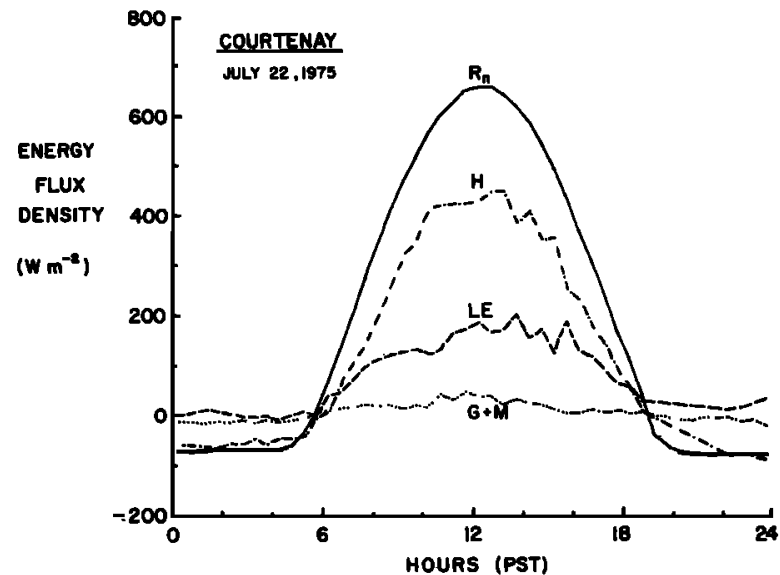

Fig. 2. Energy balance diagram for July 22 , the twenty-fourth day of the main summer drying period in 1975, at site 2 (thinned stand) at Courtenay, British Columbia. The variables are defined in the text.

observed to be, for site $1,0.12$ and $0.08^{\circ} \mathrm{C} \mathrm{m}^{-1}$, respectively, and, for site $2,0.09$ and $0.06^{\circ} \mathrm{C} \mathrm{m}^{-1}$, respectively.

Also plotted in Figure 6 are the average energy balance and water balance estimates of evapotranspiration for the Douglas fir stand at the University of British Columbia Research Forest over a 15-day period in 1970 reported by Black and McNaughton [1972]. Their reported uncertainty in the water balance estimate was $\pm 0.6 \mathrm{~mm} \mathrm{~d}^{-1}$.

\section{Effect of Soil Water and Net \\ Radiation on $E / E_{\mathrm{eq}}$}

Figures 7 and 8 show the ratio of $E$ to $E_{\text {eq }}$ plotted against water storage (the equivalent depth of water) in the root zone for sites 2 and 1 , respectively. The equilibrium evaporation rate $E_{\text {eq }}$ was calculated from (1) using 24-hour values of the available energy and mean temperature which, for site 2 , is shown in Figure 4. Because the analysis in Figure 6 suggests that the energy balance data at site 1 overestimated evapotranspiration by about $10 \%$, the evapotranspiration data used to calculate the values of $E / E_{\text {eq }}$ in Figure 8 were first decreased by $10 \%$. The values of the left-hand ends of the abscissae of Figures 7 and 8 are the estimated field capacity water storage values for the respective root zones from Table 1 . The general shape of Figures 7 and 8 is similar to that of Figures 3-5 of

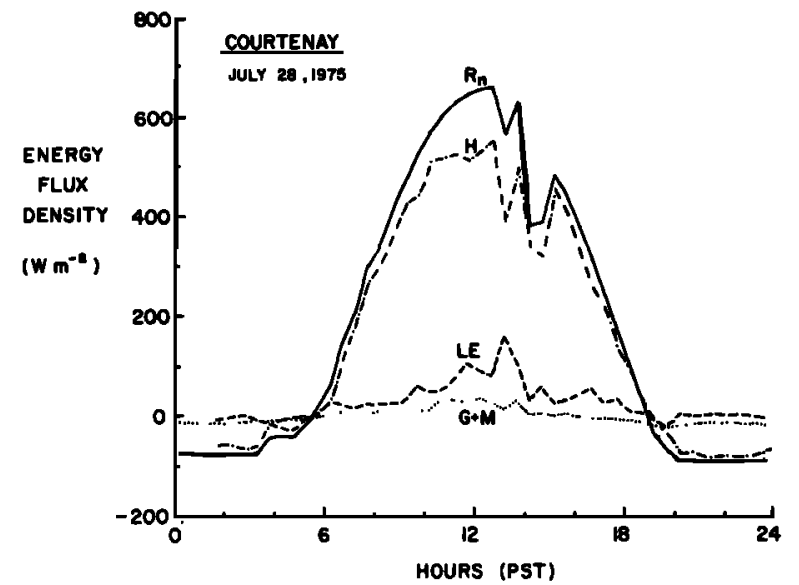

Fig. 3. Energy balance diagram for July 28 , the thirtieth day of the main summer drying period in 1975, at site 2 (thinned stand) at Courtenay, British Columbia. The variables are defined in the text. 

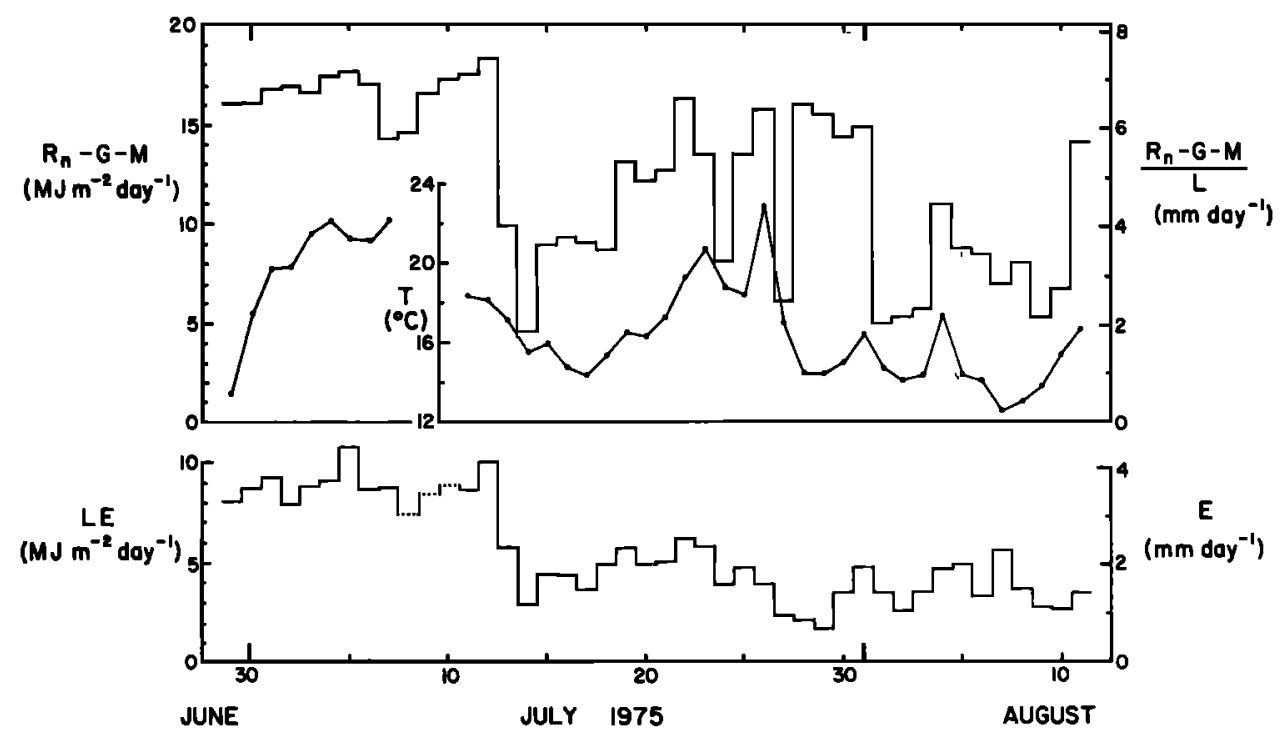

Fig. 4. Twenty-four-hour values of energy balance measurements of evapotranspiration rate $(E)$ made at site 2 in 1975. Dotted values of $E$ were estimated from a plot of $L E / R_{n}$ versus soil water matric potential using data measured at site 2 . Also shown are 24-hour values of the available energy $\left(R_{n}-G-M\right)$ and the 24-hour mean value of air temperature $(T)$ above the stand.

Priestley and Taylor [1972]. In Figures 7 and 8, there is a range of soil water storage beginning at field capacity in which $E / E_{\text {eq }}$ is relatively constant, and there is a range in which $E / E_{\text {eq }}$ decreases with decreasing soil water storage. Priestley and Taylor referred to the latter range as the drying phase. If $E / E_{\text {eq }}$ had been plotted against the accumulated evapotranspiration minus precipitation (i.e., $\int(E-P) d t$ ), as it was in Figures 3-5 of Priestley and Taylor, the shape of the graphs would be virtually unchanged. This is because the vertical flow of water into or out of the root zone at Courtenay averaged less than $10 \%$ of the evapotranspiration. (It should be noted that Priestley and Taylor were using $\int(E-P) d t$ as a meteorological estimate of the change in root zone water storage assuming that vertical soil water flow was usually small.)

Data in Figure 7 have been separated into two categories: days with a 24 -hour value of $R_{n}>12 \mathrm{MJ} \mathrm{m}^{-2} \mathrm{~d}^{-1}$ (sunny days) and those with a 24 -hour value of $R_{n}<12 \mathrm{MJ} \mathrm{m}^{-2} \mathrm{~d}^{-1}$ (cloudy days). Cloudy day data at site 1 were not considered very reliable for reasons discussed earlier, and therefore all data in Figure 8 are for sunny days. Figure 7 strongly suggests that on cloudy days, especially cloudy days following rain, $E / E_{\mathrm{eq}}$ is significantly higher than on sunny days. Unfortunately, there were no cloudy day data when soil water storage was high, so little can be said about $E / E_{\text {eq }}$ under these conditions. Other workers have reported that at a given soil water content the ratio of actual to maximum evapotranspiration increased with decreasing maximum evapotranspiration, the latter being strongly dependent on the daily net radiation [Makkink and Van Heemst, 1956; Scholte-Ubing. 1961; Denmead and Shaw, 1962]. It is interesting to note in Figure 7 that on the only sunny day after rain at site 2 (June 29,1975 ), $E / E_{\text {eq }}$ was no higher than on subsequent sunny days when soil water storage was relatively high.

\section{$E / E_{\mathrm{eq}}$ at High Soil Water Storage:} An Estimate of $E_{\max } / E_{\mathrm{eq}}$

In order to determine the average value of $E / E_{\text {ea }}$ at site 2 when evapotranspiration appeared not to be limited by the quantity of water in the root zone, the regression slope of a plot of $E$ against $E_{\text {eq }}$ was determined for all data for which

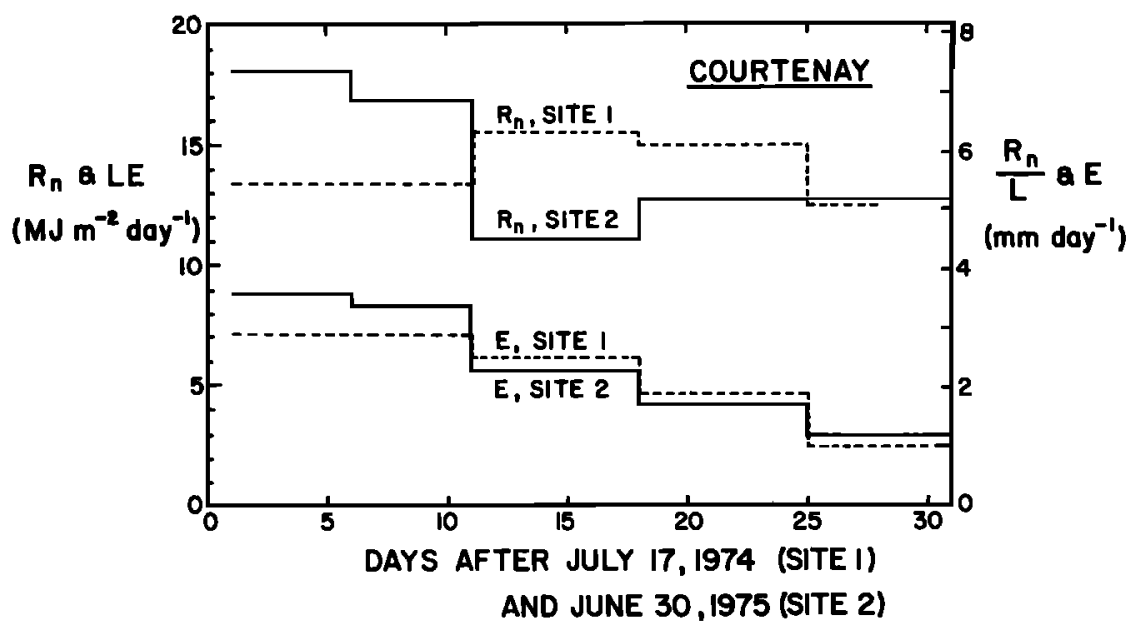

Fig. 5. Average evapotranspiration rates determined from water balance measurements during a summer drying period at site 1 (unthinned stand) in 1974 and at site 2 (thinned stand) in 1975. Also shown are averaged net radiation $\left(R_{n}\right)$ values. 


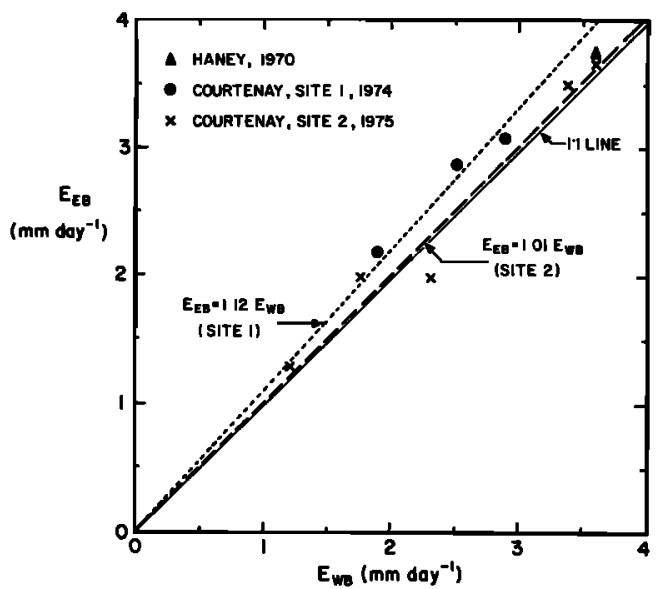

Fig. 6. Comparison of average energy balance values $\left(E_{\mathrm{EB}}\right)$ and water balance values $\left(E_{\mathrm{WB}}\right)$ of evapotranspiration rates at sites 1 and 2 . Water balance values are the same as those in Figure 5. A point corresponding to the fourth water balance time interval for site 1 in Figure 5 is missing because energy balance measurements were not made throughout this interval. Also shown are regression equations and lines for the data for both sites. A data point for a 15-day period at the University of British Columbia Research Forest at Haney, British Columbia, from Black and McNaughton [1972] is also shown.

$W>11.6 \mathrm{~cm}$. This value was selected because values of $E / E_{\mathrm{eq}}$ for larger values of $W$ showed no tendency to decrease in response to decreasing $W$. The plot of the data for these 15 days (sunny and cloudy) and the corresponding regression line is shown in Figure 9. For this range of $W$ the average value of $E / E_{\text {eq }}$ was found to be 0.797 and is shown as a horizontal line in Figure 7. In the case of site 1 the same procedure was used on the three data points for which $W>9 \mathrm{~cm}$ (see Figure 9). For this range of $W$ the average value of $E / E_{\text {eq }}(E$ data corrected) was 0.837 and is shown as the horizontal line in Figure 8.

The relationship between $E$ and $E_{\mathrm{eq}}$ for the Courtenay forest stands is compared to 1970 data for the University of British Columbia Research Forest stand (replotted from Figure 4 of McNaughton and Black [1973]) in Figure 9. McNaughton and Black found that for $\Psi_{m}>-0.3 \mathrm{bar}, E / E_{\text {eq }}$ was 1.05 . As was indicated earlier for low-growing vegetation with adequate soil water, values of this ratio tend to lie between 1.1 and 1.3 . In general, for forests the ratio appears to be less than that for crops. A good example of this is the 16-m-tall pine forest at Thetford, England, for which soil water matric potentials rarely fall below - I bar [J. B. Stewart and A. S. Thom, 1973].

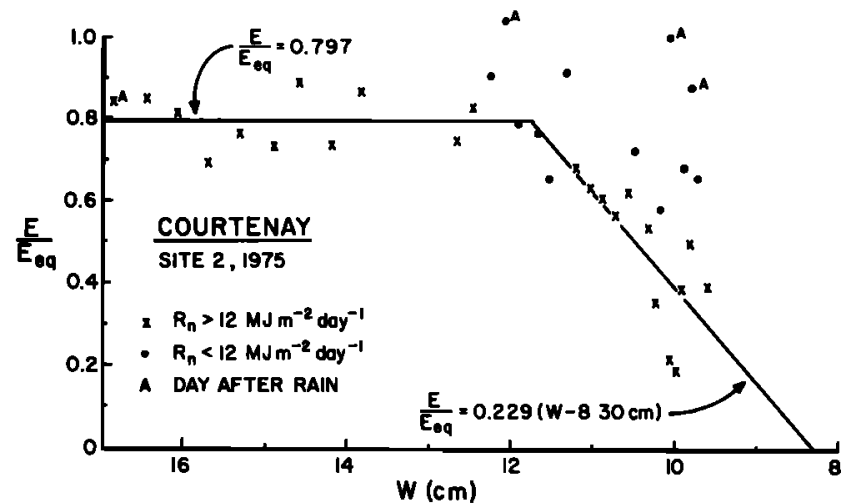

Fig. 7. Twenty-four-hour energy balance values of evapotranspiration rate $(E)$ at site 2 divided by the equilibrium evaporation rate $\left(E_{\mathrm{eq}}\right)$ plotted against the water storage in the root zone $(W)$.

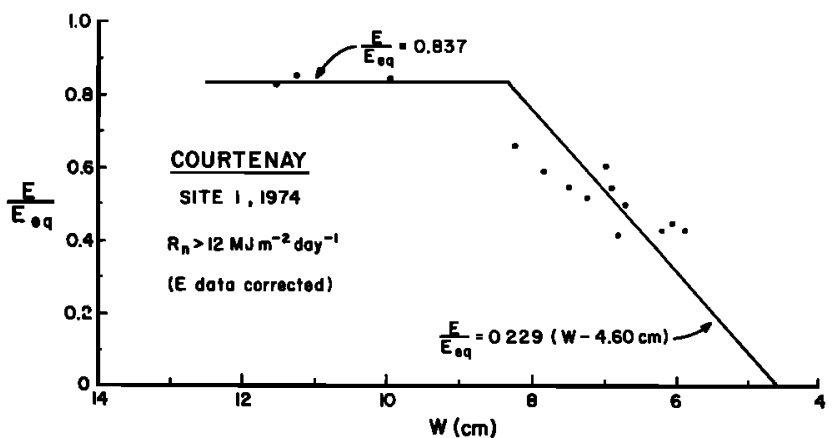

Fig. 8. Corrected 24-hour energy balance values of evapotranspiration rate $(E)$ at site 1 divided by the equilibrium evaporation rate $\left(E_{\text {eq }}\right)$ plotted against water storage in the root zone $(W)$. The correction, based on results shown in Figure 6, was a $10 \%$ reduction in $E$.

From their Figure 2 it is possible to estimate the 24-hour value of $E / E_{\mathrm{eq}}$ for this forest for two sunny days, July 7 and 8,1971 , to be 0.6 and 0.7 , respectively.

From Figures 7 and 8 it is clear that at Courtenay when soil water storage is high, $E / E_{\text {eq }}$ is significantly less than 1 . If it was not necessary to correct the site 1 data, then $E / E_{\text {eq }}$ might be as high as 0.9 for the thinned stand. However, if the correction is valid, as is strongly suggested by Figure 6, then thinned and unthinned stands at Courtenay have an $E / E_{\text {eq }}$ at high soil water storage of about 0.8 . The values of $E / E_{\text {eq }}$ reported for the Courtenay sites in this section are considered reliable estimates of $E_{\max } / E_{\text {eq }}$, since on several days, root zone soil water matric potentials were greater than -0.2 bar and one day, with the root zone at this value of matric potential, occurred immediately after a rainy day.

\section{$E / E_{\text {eq }}$ During the Drying Phase}

The straight line drawn through the data in Figure 7 for low values of $W$ is the regression line for days when $R_{n}>12 \mathrm{MJ}$ $\mathrm{m}^{-2} \mathrm{~d}^{-1}$. While there is considerable scatter at low values of $W$, a straight line provides an approximate description of the sunny day data. The variation in $E / E_{\text {eq }}$ at low $W$ is not simply experimental error in the energy balance measurements. Calculations of evapotranspiration for July 28, 29, and 30, 1975, using a stomatal resistance-vapor pressure deficit model, agreed very closely with energy balance measurements [Tan et $a l ., 1978]$, values of $E / E_{\text {eq }}$ being $0.22,0.19$, and 0.39 , respectively, while the corresponding values of $W$ were $10.08,10.00$,

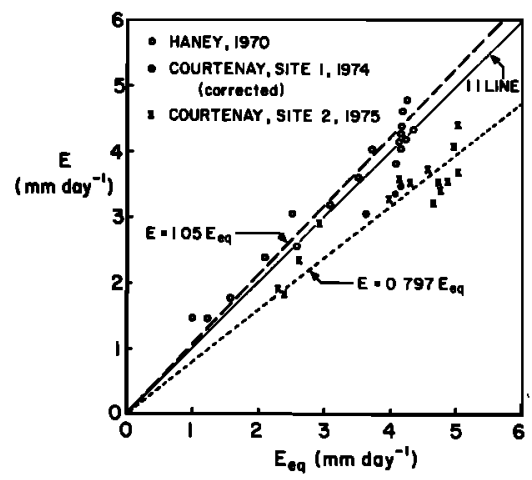

Fig. 9. Twenty-four-hour energy balance values of evapotranspiration rate $(E)$ before the start of the drying phase at sites 1 and 2 plotted against equilibrium evaporation rate. Also shown are data from McNaughton and Black [1973] for the University of British Columbia Research Forest at Haney, British Columbia. 
TABLE 2. Summary of Graphical Analysis Used to Estimate the Extractable Soil Water in the Root Zone at Sites I and 2

\begin{tabular}{|c|c|c|c|}
\hline & $\begin{array}{c}\text { Field } \\
\text { Capacity } \\
\left(-\frac{1}{3} \text { bar }\right)\end{array}$ & $\begin{array}{c}\text { Zero } \\
\text { Extraction } \\
\text { Point }\end{array}$ & $\begin{array}{c}\text { Extractable } \\
\text { Water }\end{array}$ \\
\hline \multicolumn{4}{|c|}{ Site 1} \\
\hline $\begin{array}{l}\theta \\
W, \mathrm{~cm}\end{array}$ & $\begin{array}{l}0.215 \\
14.0\end{array}$ & $\begin{array}{l}0.071 \\
4.6\end{array}$ & $\begin{array}{l}0.144 \\
9.4\end{array}$ \\
\hline \multicolumn{4}{|c|}{ Site 2} \\
\hline$\theta$ & 0.213 & 0.104 & 0.109 \\
\hline$W, \mathrm{~cm}$ & 17.0 & 8.3 & 8.7 \\
\hline
\end{tabular}

The values of $W$ at the zero extraction point $\left(W_{m}\right)$ are shown in Figure 7 (site 2) and Figure 8 (site 1).

and $9.92 \mathrm{~cm}$, respectively. Possible reasons for this variability were discussed in the section on energy balance measurements. Because of a lack of data for site $I$ it was decided that the slope of the line drawn through the data at low $W$ (Figure 8) would be the same as that for site 2 shown in Figure 7 (i.e., 0.229 $\mathrm{cm}^{-1}$ ). This slope appears to describe the data of site 1 reasonably well.

Extrapolation of the sloping lines in Figures 7 and 8 through $E / E_{\text {eq }}=0$ provides an estimate of the point of zero water extraction, $W_{m}$ (i.e., the minimum water storage when water extraction has practically stopped). The intersection of sloping and horizontal lines in these figures provides an estimate of the critical point, $W_{c}$ (i.e., the water storage when $E / E_{\text {eq }}$ begins to decrease in response to decreasing $W$ ). Tables 2 and 3 list the values of $W_{m}$ and $W_{c}$ for both sites. Because root zone depth and retention properties of the soil at the two sites are slightly different (see Table 1), it is not surprising that the value of $W$ at the critical point and the zero extraction point are different. It is of interest to note that the critical point was reached at both sites about 12 days after the dry period began. This similarity is quite fortuitous, since at site 1 the soil was about $2.5 \mathrm{~cm}$ less than field capacity at the beginning of the period and the net radiation at site 1 over the 12 -day period was $20 \%$ less than that at site 2 . At sites 1 and 2 the quantity of water extractable between field capacity and the critical point is about 5.7 and $5.2 \mathrm{~cm}$, respectively, while the quantity of water extractable between the critical point and the zero extraction point is about 3.7 and $3.5 \mathrm{~cm}$, respectively (Tables 2 and 3 ). The latter figures compare with a value of $5 \mathrm{~cm}$ found by Priestley and Taylor [1972] for various combinations of agricultural crops and soils.

Figure 10 shows $E / E_{\text {eq }}$ on sunny days for both sites plotted against fractional extractable water in the root zone $\left(\theta_{e}\right)$ as calculated from (2). The corrected values of the data from site 1 have been used in this figure. The two lines drawn through the data are the same as those in Figure 7. The relationship

TABLE 3. Critical Point Values of the Root Zone Water Storage $\left(W_{c}\right)$, the Average Volumetric Water Content of the Root Zone $\left(\theta_{c}\right)$, the Fraction of Extractable Water Remaining in the Root Zone $\left(\theta_{e c}\right)$ and the Maximum and Minimum Values of the Root Zone Soil Water Matric Potential $\left(\Psi_{m}\right)$

\begin{tabular}{lccccc}
\hline & & & & \multicolumn{2}{c}{$\Psi_{m}$, bars } \\
\cline { 5 - 6 } & $W_{c}, \mathrm{~cm}$ & $\theta_{c}$ & $\theta_{e c}$ & Maximum & Minimum \\
\hline Site 1 & 8.3 & $\mathbf{0 . 1 3}$ & 0.39 & -1.1 & -3.4 \\
Site 2 & 11.8 & 0.15 & 0.40 & -1.2 & -3.0 \\
\hline
\end{tabular}

The values of $W_{c}$ are taken from Figures 7 and 8.

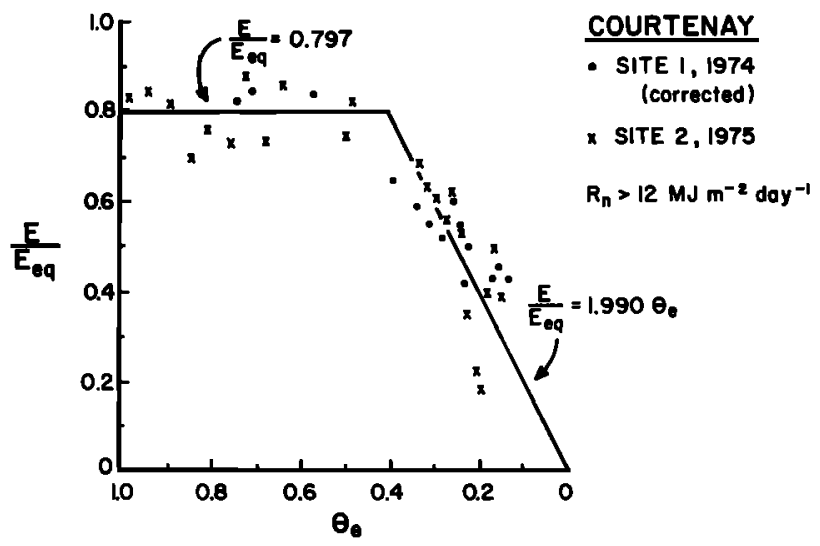

Fig. 10. A plot of sunny day values of $E / E_{\text {eq }}$ from Figures 7 and 8 against the fractional extractable water remaining in the root zone $\left(\theta_{e}\right)$.

between $E / E_{\text {eq }}$ and soil water content at the two sites appears to be very similar when they are compared on the basis of fractional extractable water. Figure 10 suggests that the critical point at the two sites occurs when there is about $40 \%$ of the extractable water left in the root zone, or $\theta_{e c} \approx 0.4$ (see also Table 3). Tanner and Ritchie [1974] concluded from their survey of crop water use experiments that a useful average value of $\theta_{e c}$ for crops was 0.3 .

How do the values of the soil water matric potential in the root zone compare at the occurrence of the critical point at the two sites? At site 1 they varied from -1.1 bars near the bottom of the root zone to -3.4 bars near the top, while at site 2 the values were -1.2 and -3.0 bars, respectively. Since these pairs of values are very similar, it would seem reasonable to compare values of $E / E_{\mathrm{eq}}$ at the two sites for given values of soil water matric potential. Several workers have related relative evapotranspiration rates to soil water potential [e.g., $\mathrm{Van} \mathrm{Ba}$ vel, 1967; Tan and Black, 1976]. One problem with this approach is that matric potentials within the root zone are rarely constant with depth. The problem is then characterizing the root zone with a meaningful average matric potential. Figure 11 shows 24-hour values of $E / E_{\text {eq }}$ on sunny days (from Figures 7 and 8) plotted against the range of $\Psi_{m}$ values found in the root zone on the day for which each value of $E / E_{\text {eq }}$ was determined. (The diurnal variation in $\Psi_{m}$ at any depth was negligible in comparison to the ranges shown in Figure 11.) Considering the magnitude of the ranges shown in Figure 11 it

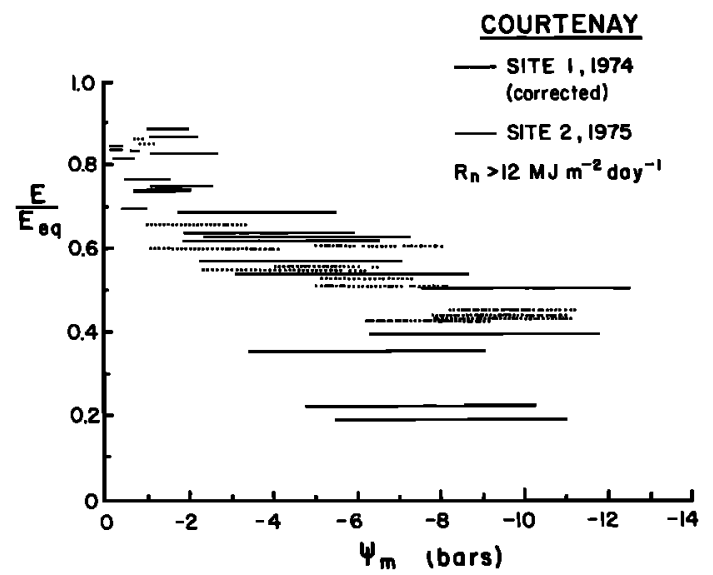

Fig. 11. A plot of sunny day values of $E / E_{\text {eq }}$ from Figures 7 and 8 against the range of soil water matric potentials $\left(\Psi_{m}\right)$ observed in the root zone. 
is clear that an arithmetic average $\Psi_{m}$ for the root zone has limited meaning. The concept of using a total root zone water storage or fractional extractable water to describe the water status of the root zone appears to be somewhat more useful in the empirical approach described in this paper. Furthermore, $W$ can be obtained by a simple water balance method without the need to use soil water retention information. Figure 11 shows that as $E / E_{\text {eq }}$ drops, matric potential gradients increase in the root zone. Both sites show a similar pattern. In addition, Figure 11 confirms the earlier remark that when maximum root zone matric potentials fall to slightly less than -1 bar, $E / E_{\text {eq }}$ begins to decline below maximum values at both sites.

\section{ConClusion}

The analysis in this paper indicates that micrometeorological energy balance estimates of forest evapotranspiration agree well with water balance estimates. The separation distance between the sensing heads of Bowen ratio measurement apparatus should be no less than $3 \mathrm{~m}$ for reliable measurements above forest stands as aerodynamically rough as those in this study.

The maximum 24-hour rate of evapotranspiration under sunny conditions at the two Courtenay sites was less than the equilibrium rate of evaporation, even on a day following rain. In the case of the thinned stand, the average value of the ratio of the maximum rate of evapotranspiration to the equilibrium evaporation rate was $0.8 \mathrm{In}$ the case of the unthinned stand, this ratio was 0.9 ; however, water balance data suggested that this was as much as $10 \%$ too high.

During the drying phase at both sites, $E / E_{\text {eq }}$ was, to a good approximation, a linear function of water storage in the root zone. Approximately $3.5 \mathrm{~cm}$ of water was still extractable from the root zone after the critical water storage value had been reached at both sites. Both sites exhibited a very similar relationship between $E / E_{\text {eq }}$ and soil water storage when soil water storage was expressed as a fraction of the extractable soil water. The critical point at both sites occurred when there was approximately $40 \%$ of the extractable water remaining in the root zone. This appears to be higher than most values reported for agricultural crops. The critical point at both sites corresponded to a maximum root zone matric potential of a little less than -1 bar.

Acknowledgments. This research was supported by grants from the National Research Council of Canada and the British Columbia Department of Agriculture and by a contract from the Canadian Forestry Service (Department of the Environment). I acknowledge the advice and cooperation of $\mathbf{H}$. Brix and $\mathbf{M}$. Crown of the Canadian Forestry Service and the foresters of the Crown Zellerback Company. I am grateful to J. U. Nnyamah and C. S. Tan for making available to me data obtained during their Ph.D. research projects at the University of British Columbia.

\section{REFERENCES}

Black, T. A., and K. G. McNaughton, Psychrometric apparatus for Bowen ratio determination over forests, Boundary Layer Meteorol. 2, 246-254, 1971.
Black, T. A., and K. G. McNaughton, Average Bowen-ratio methods of calculating evapotranspiration applied to a Douglas fir forest, Boundary Layer Meteorol., 2, 466-475, 1972.

Davies, J. A., and C. D. Allen, Equilibrium, potential and actual evaporation from cropped surfaces in southern Ontario, J. Appl. Meteorol. 12, 649-657, 1973.

Denmead, O. T., and R. H. Shaw, Availability of soil water to plants as affected by soil moisture content and meteorological conditions, Agron. J., 54, 385-390, 1962.

Gardner, W. R., and C. F. Ehlig, The influence of soil water on transpiration by plants, J. Geophys. Res., 68, 5719-5724, 1963.

Jury, W. A., and C. B. Tanner, A modification of the Priestley and Taylor evapotranspiration formula, Agron. J., 67, 840-842, 1975.

Makkink, G. F., and H. D. J. Van Heemst, The actual evapotranspiration as a function of the potential evapotranspiration and the soil moisture tension, Neth. J. Agr. Sci., 4, 67-72, 1956.

McNaughton, K. G., Evaporation and advection, I, Evaporation from extensive homogeneous surfaces, Quart. J. Roy. Meteorol. Soc., 102, 181-191, 1976.

McNaughton, K. G., and T. A. Black, A study of evapotranspiration from a Douglas fir forest using the energy balance approach, Water Resour. Res., 9, 1579-1590, 1973.

Nnyamah, J. U., and T. A. Black, Rates and patterns of water uptake in a Douglas fir forest, Soil Sci. Soc. Amer. J., 41. 972-979, 1977.

Penman, H. L., Natural evaporation from open water, bare soil and grass, Proc. Roy. Soc. London, Ser. A, 193, 120-146, 1948.

Priestley, C. H. B., and R. J. Taylor, On the assessment of surface heat flux and evaporation using large-scale parameters, Mon. Weather Rev., 100, 81-92, 1972.

Ritchie, J. T., Influence of soil water status and meteorological conditions on evaporation from a corn canopy, Agron. J., 65, 893-897, 1973.

Ritchie, J. T., E. Burnett, and R. C. Henderson, Dryland evaporative flux in a subhumid climate, III, Soil water influence, Agron. J., 64 , 168-173, 1972.

Scholte-Ubing, D. W., Solar and net radiation, available energy and its influence on evapotranspiration from grass, Neth. J. Agr. Sci., 9 $81-93,1961$.

Slatyer, R. O., and I. C. Mcllroy, Practical microclimatology, report, 328 pp., Counc. for Sci. and Ind. Res., Plant Ind. Div., Canberra, Australia, 1961.

Stewart, J. B., and A. S. Thom, Energy budgets in pine forest, Quart. J. Roy. Meteorol. Soc., 99, 154-170, 1973.

Stewart, R. B., and W. R. Rouse, Substantiation of the Priestley and Taylor parameter $\alpha=1.26$ for potential evaporation at high latitudes, J. Appl. Meteorol., 16, 649-650, 1977.

Tan, C. S., and T. A. Black, Factors affecting the canopy resistance of a Douglas-fir forest, Boundary Layer Meteorol., 10,475-488, 1976.

Tan, C. S., T. A. Black, and J. U. Nnyamah, A simple diffusion model of transpiration applied to a thinned Douglas-fir stand, Ecology, 59, in press, 1978.

Tanner, C. B., and W. L. Pelton, Potential evapotranspiration by the approximate energy balance method of Penman, J. Geophys. Res. $65,3391-3413,1960$

Tanner, C. B., and J. T. Ritchie, Evapotranspiration: Empiricisms and modeling, paper presented at Annual Meeting, Amer. Soc. of Agron., Chicago, Ill., Nov, 1974.

Van Bavel, C. H. M., Changes in canopy resistance to water loss from alfalfa induced by soil water depletion, Agr. Meteorol., 4, 165-176, 1967.
(Received June 13, 1978;

revised August 25, 1978; accepted September 18, 1978.) 